NOTE TO THE EDITOR

\title{
Evaluation of indigenous bacterial strains for biocontrol of the frogeye leaf spot of soya bean caused by Cercospora sojina
}

\author{
E. Simonetti ${ }^{1}$, M.A. Carmona ${ }^{2}$, M.M. Scandiani ${ }^{3}$, A.F. García ${ }^{4}$, A.G. Luque $^{5}$, O.S. Correa ${ }^{1}$ and K.B. \\ Balestrasse $^{4,6}$ \\ 1 Cátedra de Microbiología Agrícola/INBA (CONICET/UBA), Facultad de Agronomía, Universidad de Buenos Aires, Buenos Aires, Argentina \\ 2 Cátedra de Fitopatología, Facultad de Agronomía, Universidad de Buenos Aires, Buenos Aires, Argentina \\ 3 Laboratorio Agrícola Río Paraná, San Pedro, Buenos Aires, Argentina \\ 4 Instituto de Investigaciones en Biociencias Agrícolas y Ambientales INBA (CONICET/UBA), Buenos Aires, Argentina \\ 5 Centro de Referencia en Micología, Universidad Nacional de Rosario, Santa Fe, Argentina \\ 6 Departamento de Química Biológica, Facultad de Farmacia y Bioquímica, Universidad de Buenos Aires, Buenos Aires, Argentina
}

\section{Keywords}

Bacillus amyloliquefaciens, biological control, Cercospora sojina, frogeye leaf spot,

Pseudomonas fluorescens.

\section{Correspondence}

Ester Simonetti, Av. San Martín 4453, C1417DSE Buenos Aires, Argentina. E-mail: simonetti@agro.uba.ar

2012/0341: received 23 February 2012, revised 3 May 2012 and accepted 4 May 2012

doi:10.1111/j.1472-765X.2012.03266.x

\begin{abstract}
Aims: Assessment of biological control of Cercospora sojina, causal agent of frogeye leaf spot (FLS) of soya bean, using three indigenous bacterial strains, BNM297 (Pseudomonas fluorescens), BNM340 and BNM122 (Bacillus amyloliquefaciens).

Methods and Results: From cultures of each bacterial strain, cell suspensions and cell-free supernatants were obtained and assayed to determine their antifungal activity against C. sojina. Both mycelial growth and spore germination in vitro were more strongly inhibited by bacterial cell suspensions than by cellfree supernatants. The Bacillus strains BNM122 and BNM340 inhibited the fungal growth to a similar degree $(I \sim 52-53 \%)$, while cells from P. fluorescens BNM297 caused a lesser reduction $(I \sim 32-34 \%)$ in the fungus colony diameter. The foliar application of the two Bacillus strains on soya bean seedlings, under greenhouse conditions, significantly reduced the disease severity with respect to control soya bean seedlings and those sprayed with BNM297. This last bacterial strain was not effective in controlling FLS in vivo.

Conclusions: Our data demonstrate that the application of antagonistic bacteria may be a promising and environmentally friendly alternative to control the FLS of soya bean.

Significance and Impact of the Study: To our knowledge, this is the first report of biological control of $C$. sojina by using native Bacillus strains.
\end{abstract}

\section{Introduction}

Frogeye leaf spot (FLS) of soya bean (Glycine max (L.) Merr.), caused by the fungus Cercospora sojina Hara, occurs worldwide and is most severe in countries of warm and humid climate (Akem et al. 1992; Ma 1994). In Argentina, during the 2009-2010 growing season, this disease spread rapidly throughout most soya bean-growing areas of provinces of Córdoba, Santa Fe and Buenos Aires (Carmona et al. 2009), becoming the main disease in the soya bean crop history of this country.
The disease can be controlled chemically, but the cost of pesticides, environmental pollution and consumer demand for safer and healthier food has led to the search for substitutes for conventional synthetic inputs. The use of beneficial micro-organisms to control plant diseases (biological control) is thus considered as an alternative or a supplemental way of reducing the use of chemicals. At present, there is an extensive literature which describes the potential uses of plant-associated bacteria for stimulating plant growth and managing soil and plant health (Glick 1995; Sturz et al. 2000; Welbaum et al. 2004). 
Root-colonizing bacteria that exert beneficial effects on plant development are known as plant growth-promoting rhizobacteria (PGPR, Kloepper and Schroth 1978).

The main recognized mechanisms of suppression of phytopathogens mediated by PGPR are the competition for nutrients or specific niches on the root, production of inhibitory allelochemicals, and induction of systemic resistance in host plants (Iavicoli et al. 2003; Meziane et al. 2005).

In a previous study, we isolated, identified and functionally characterized indigenous bacterial strains with antifungal activity from the soya bean rhizosphere. Three of these isolates, designated as Pseudomonas fluorescens BNM297, P. fluorescens BNM296 and Bacillus amyloliquefaciens BNM340, were tested as seed inoculants, showing BNM296 and BNM340 effective suppression capacity against damping-off caused by Pythium ultimum in soya bean (León et al. 2009).

Additionally, in our laboratory, it was demonstrated that the strain BNM122 of B. amyloliquefaciens, isolated from a sclerotium of Sclerotinia sclerotiorum, excretes metabolites that suppress mycelial growth of numerous fungal species and also exhibits, by application onto soya bean seeds, protective effect against the damping-off produced by Rhizoctonia solani (Souto et al. 2004).

Most of the research made on biological control of soya bean pathogens has focused on soilborne fungal pathogens, whereas very little is known about the efficacy of this method for controlling foliar diseases. Particularly for C. sojina, there are no published studies related to biological control.

In this study, three of the previously characterized indigenous bacterial strains, BNM340, BNM122 and BNM297, were assessed for their ability to inhibit C. sojina CCC 172-09 (Culture Collection of CEREMIC, Centro de Referencia de Micología, Rosario, Argentina) growth in vitro and to control FLS disease development in vivo on susceptible soya bean plants.

To evaluate in vitro the antifungal activity of living cells and cell-free supernatants from the three bacterial strains separately, the cells were harvested by centrifugation and adjusted to $10^{8} \mathrm{CFU} \mathrm{ml}^{-1}$ in sterile distilled water (SDW). In turn, the supernatants were filtrated through $0 \cdot 22 \mu \mathrm{m}$ MILLEX ${ }^{\circledR} \mathrm{GP}$ filter units (Millipore, Carrigtwohill, Co. Cork, Ireland).

Mycelial growth inhibition was tested by the dual plate assay method (Huang and Hoes 1976). A five millimetre in diameter agar disc of freshly grown C. sojina fungus was placed at the centre of a potato dextrose agar (PDA) plate and allowed to grow to $2-3 \mathrm{~cm}$ in diameter for approximately 6 days. Three microlitres of the standardized cell suspensions (SS) or $10 \mu \mathrm{l}$ of the cell-free filtrates (CF) of the bacterial strains were placed in a straight line at $3 \mathrm{~cm}$ apart and on both sides of the mycelial plug. After an incubation period of 10 days at $20^{\circ} \mathrm{C}$, the mycelium growth inhibition in percentage $(I)$ was calculated.

Effect of bacteria on C. sojina spore germination was tested by mixing in test tubes the SS or CF of the bacterial strains with a conidial suspension in SDW $\left(1 \cdot 0 \times 10^{5}\right.$ spores $\left.\mathrm{ml}^{-1}\right)$ in $1: 5$ proportion $(\mathrm{v} / \mathrm{v})$. The mixtures were incubated at $25^{\circ} \mathrm{C}$ in darkness. The control treatment consisted of suspensions of C. sojina spores in sterile water. After 24 and $72 \mathrm{~h}$ of co-cultivation, $45-\mu \mathrm{l}$ aliquots were placed on microscope slides and observed under a light microscope. Per cent of spore germination was determined in different microscopic fields with a total of 100 spores per replicate.

The in vitro tests were performed in triplicate, and data were analysed by analysis of variance (ANOvA) and Tukey's test $(P<0.05)$, using InfoStat/Profesional software, ver. 2011 (Facultad de Ciencias Agropecuarias, Universidad de Córdoba, Argentina).

The SS of the three bacterial strains significantly reduced mycelial growth of C. sojina isolate CCC 172-09. Bacillus BNM122 and BNM340 inhibited the fungus to a similar degree $(I \sim 52-53 \%)$, while cells from BNM297 produced a lesser reduction $(I \sim 32-34 \%)$ in the fungus colony diameter.

The CF from BNM122 showed a low antifungal activity (I 20-22\%) compared to SS. The BNM340 supernatant slightly affected the fungus colony diameter, whereas BNM297 CF had no effect on C. sojina growth. One plausible explanation for the discrepancy observed between this result and that obtained when we tested the SS of these strains might be that bacteria inhibit the fungus growth by competing for nutrient availability. Another plausible explanation is that bacteria produce antifungal volatile compounds or posses enzymatic activities that may have been lost when filtrates were obtained. Indeed, in a previous work, León et al. (2009) demonstrated that the strain BNM297 produces volatile compounds such as hydrogen cyanide.

As observed for the mycelium growth, the inhibitory effect of SS on conidial germination was considerably stronger than that caused by bacterial CF. After 24 and $72 \mathrm{~h}$ of co-cultivation with SS from BNM297, BNM340 or BNM122, a significant inhibition of conidial germination was observed ( $I \sim 79 \%, 79 \%$ and $89 \%$, respectively).

CF from BNM340 and BNM297 did not inhibit conidial germination compared to the water control, while BNM122 supernatant caused only a moderate reduction ( $I \sim 26 \%)$ in conidial germination. From these results, we may postulate that the presence of bacteria is necessary for conidial inhibition, maybe some particular component that is present in the bacterial envelope.

Biocontrol tests in vivo were conducted with cultivar NIDERA A 4613RG that is very susceptible to C. sojina. 
Five vigorous plants per pot were placed on a greenhouse bench under natural photoperiod at $25 \pm 5^{\circ} \mathrm{C}$. Four replicates for each treatment were arranged in a block design along a light gradient. Treatments included foliar application (approximately $5 \mathrm{ml}$ ) of (i) P. fluorescens BNM297 (ii) B. amyloliquefaciens BNM340, (iii) B. amyloliquefaciens BNM122 suspensions or (iv) sterile water (nonbacterized control) at 21 days after seedling emergence. Bacterial suspensions $\left(1.0 \times 10^{9} \mathrm{CFU} \mathrm{ml}{ }^{-1}\right)$ were prepared by mixing $20 \mathrm{ml}$ of each bacterial culture with $50 \mathrm{ml}$ of SDW and $0.5 \%$ of sterile vegetable oil as previously described (Sydorenko 2010).

It was previously reported that $C$. sojina conidia can germinate on a leaf surface within an hour of deposition in the presence of water (Mian et al. 2008). For this reason, in the present work, we considered the application of bacteria as a preventive method since once the pathogen colonizes internal tissues would be difficult to attain an effective biological control.

Twenty-four hours postbacterial application, once probed that bacteria colonized the leaf surfaces, plants were inoculated with $1 \mathrm{ml}$ of a $C$. sojina conidial suspension $\left(7.6 \times 10^{4}\right.$ conidia $\left.\mathrm{ml}^{-1}\right)$ in SDW and a drop of Tween 20 as dispersant. In addition to this, negative (uninfected plants, pretreated or not with bacteria) and positive controls (nonbacterized plants inoculated with C. sojina) were included. Plants were kept in moist chamber $72 \mathrm{~h}$ after inoculation to maintain high humidity and facilitate fungal infection.

Symptoms on the second trifoliate leaves were assessed 20 days after fungal inoculation. Disease severity was estimated as percentage of the central leaflet area affected with lesions. Data from two independent experiments were rank-transformed to meet the assumption of normality and then subjected to ANovA. Means were compared by Tukey's test $(P<0.05)$ Symptoms observed on inoculated leaves were circular, reddish brown-to-grey spots $(1-6 \mathrm{~mm})$ and bordered by typical, narrow, reddish purple margins. Foliar lesions and morphological characteristics of the pathogen were consistent with C. sojina. No symptoms were observed on negative controls.

The three bacterial strains were able to effectively colonize the leaf surfaces at $24 \mathrm{~h}$ postinoculation at levels of $7 \cdot 7,6 \cdot 3$ and $7 \cdot 7 \log _{10} \mathrm{CFU} \mathrm{g}{ }^{-1}$ (leaf fresh weight), respectively. Colony counts performed from nonbacterized control plants revealed absence of colonies morphologically similar to any of the bacterial strains assayed.

Both spray-applied bacteria, BNM340 and BNM122, significantly reduced the disease severity to a similar degree with respect to positive control plants, showing no significant differences between them, while P. fluorescens BNM297 did not exert any effect on the disease severity of FLS on soya bean plants (Table 1).
Table 1 Effect of foliar application of bacterial suspensions on disease severity on soya bean plants inoculated with Cercospora sojina under greenhouse conditions

\begin{tabular}{ll}
\hline Treatment & Severity (\%)* \\
\hline Control (SDW) & $5 \cdot 11^{\mathrm{a}}$ \\
Pseudomonas fluorescens BNM297 & $3 \cdot 45^{\mathrm{a}}$ \\
Bacillus amyloliquefaciens BNM340 & $0 \cdot 48^{\mathrm{b}}$ \\
Bacillus amyloliquefaciens BNM122 & $0 \cdot 88^{\mathrm{b}}$ \\
\hline
\end{tabular}

SDW, sterile distilled water.

*Disease severity was assessed at 20 days postfungal inoculation as percentage of central leaflet area affected. Data are mean values of two independent experiments. Data were rank-transformed to meet the ANOVA assumption of normality. Different letters within columns indicate significant differences ( $P=0.0002)$ according to Tukey's test.

Although the three evaluated bacterial strains effectively colonized soya bean leaves at the time of fungal inoculation, they exhibited different capacities for the biocontrol of FLS disease. The treatment with BNM297 strain that significantly inhibited C. sojina growth on PDA medium did not affect disease severity of FLS. These discrepancies between tests in vitro and in vivo are frequently reported in the literature (Janisiewicz 1987; Dal Bello et al. 2008). The loss of BNM297 biocontrol capacity may be due to its inability to activate the antifungal mechanisms on the plant leaves. These findings highlight the need to corroborate the results obtained in vitro by testing them under natural conditions.

Our results suggest that the application of antagonistic bacteria, as a preventive method, may be considered a viable option for FLS disease management overlooking environmentally sustainable and eco-friendly systems, because of its cost-effectiveness, lower pollution and residual toxicity than those caused by synthetic fungicides. To the best of our knowledge, this is the first report of biological control of C. sojina by application of indigenous Bacillus strains.

Given that soya bean crop is being massively produced in Argentina and, accordingly, the use of fungicides is increasing, this study contributes to the development of biological control strategies to decrease the use of synthetic fungicides in soya bean crop.

Further studies will focus on the mechanisms by which these bacterial strains preventively reduce FLS and also assays under different field conditions, to better predict the behaviour of these biocontrol agents and propose their use as a biological alternative to prevent this disease.

\section{Acknowledgements}

This research was supported in part by 'Fondo para la Investigación Científica y Tecnológica' (FONCYT, project 
PICT2007/443); UBACyT proyect 20020100100493; fellowship from Consejo Nacional de Investigaciones Científicas y Técnicas (CONICET) to ES; KBB is career Investigator of CONICET, Argentina.

\section{References}

Akem, C.N., Dashill, K.E. and Uwala, A.C. (1992) Prevalence of frogeye leaf spot of soya bean in Nigeria. Int J Tropical Plant Dis 10, 181-183.

Carmona, M.A., Scandiani, M. and Luque, A. (2009) Severe outbreaks of soybean frogeye leaf spot caused by Cercospora sojina in the pampean region, Argentina. Plant Dis 93, 966.

Dal Bello, G., Monaco, C. and Rollan, M.C. (2008) Biocontrol of postharvest grey mould on tomato by yeasts. Phytopathology 156, 257-263.

Glick, B. (1995) The enhancement of plant growth by free-living bacteria. Can J Microbiol 41, 109-117.

Huang, H.C. and Hoes, J.A. (1976) Penetration and infection of Sclerotinia sclerotiorum by Coniothyrium minitans. Can J Bot 54, 406-410.

Iavicoli, A., Boutet, E., Buchala, A. and Métraux, J.P. (2003) Induced systemic resistance in Arabidopsis thaliana in response to root inoculation with Pseudomonas fluorescens CHA0. Mol Plant Microbe Interact 16, 851-858.

Janisiewicz, W. (1987) Postharvest biological control of blue mold on apples. Phytopathology 77, 481-485.

Kloepper, J.W. and Schroth, M.N. (1978) Plant growth-promoting rhizobacteria on radishes. In Station de Pathologie Vegetale et Phyto-Bacteriologie. Proceedings of the 4th
International Conference on Plant Pathogenic Bacteria, vol. II. pp. 879-882. Tours, France: Gilbert-Clarey.

León, M., Yaryura, P.M., Montecchia, M.S., Hernández, A.I., Correa, O.S., Pucheu, N.L., Kerber, N.L. and García, A.F. (2009) Antifungal activity of selected indigenous Pseudomonas and Bacillus from the soybean rhizosphere. Int Microbiol 2009, Article ID 572049. doi: 10.1155/2009/572049.

Ma, G.Z. (1994) Review and forecast of study on frogeye leaf spot. Soybean J 1, 6-7.

Meziane, H., van der Sluis, I., van Loon, L.C., Höfte, M. and Bakker, P.A.H. (2005) Determinants of Pseudomonas putida WCS358 involved in inducing systemic resistance in plants. Mol Plant Pathol 6, 177-185.

Mian, M.A.R., Missaoui, A.M., Walker, D.R., Phillips, D.V. and Boerma, H.R. (2008) Frogeye leaf spot of soybean: a review and proposed race designations for isolates of Cercospora sojina Hara. Crop Sci 48, 14-24.

Souto, G.I., Correa, O.S., Montecchia, M.S., Kerber, N.L., Pucheu, N.L., Bachur, M. and Garcia, A.F. (2004) Genetic and functional characterization of a Bacillus sp. strain excreting surfactin and antifungal metabolites partially identified as iturin-like compounds. J Appl Microbiol 97, 1247-1256.

Sturz, A.V., Christie, B.R. and Nowak, J. (2000) Bacterial endophytes: potential role in developing sustainable systems of crop production. Crit Rev Plant Sci 19, 1-30.

Sydorenko, O. (2010) Formulación de inoculantes de Bacillus amyloliquefaciens BNM122 para el control biológico de fitopatógenos. Undergraduate.

Welbaum, G., Sturz, A.V., Dong, Z. and Nowak, J. (2004) Fertilizing soil microorganisms to improve productivity of agroecosystems. Crit Rev Plant Sci 23, 175-193. 